\title{
Estudo morfossintático de cartas de inábeis do sertão baiano (século xx): o artigo definido diante de sintagma nominal
}

\author{
Morphosynthetic study of unavailable letters from sertão baiano (century $x x$ ): \\ the article defined before nominal syntagma
}

\author{
Rosana Carvalho Brito* \\ Universidade Estadual de Feira de Santana \\ Feira de Santana, Bahia, Brasil \\ Mariana Fagundes de Oliveira Lacerda* \\ Universidade Estadual de Feira de Santana \\ Feira de Santana, Bahia, Brasil \\ Zenaide de Oliveira Novais Carneiro*** \\ Universidade Estadual de Feira de Santana \\ Feira de Santana, Bahia, Brasil
}

\begin{abstract}
Resumo: A variação presença/ausência do artigo definido antes de possessivos e antropônimos é largamente observada no português brasileiro, diferenciando-o do português europeu, que marca obrigatoriamente o artigo nesses contextos. No Brasil, as pesquisas desenvolvidas até o momento, de um modo geral, relacionam essa variação à questão da especificidade. Avançam na análise então os estudos que apontam para outros aspectos condicionantes da presença ou ausência do artigo, a exemplo do trabalho de Callou e Silva (1997). Neste artigo, visando colaborar para compreensão desse tema, apresentam-se os resultados parciais de uma pesquisa que vem sendo desenvolvida no âmbito do Programa de Mestrado em Estudos Linguísticos da Universidade Estadual de Feira de Santana (PPGEL/UEFS), cujo objetivo é analisar a variação presença/ausência do artigo definido em 91 cartas pessoais, editadas por Santiago (2012), corpus de extrema relevância para os estudos linguísticos, por se constituir dos produtos gráficos de pessoas semianalfabetas e poder fornecer indícios do português popular brasileiro.
\end{abstract}

Palavras-chave: Artigo definido. Cartas de mãos inábeis. Corpora do português popular.

\begin{abstract}
The presence or absence variation of the definite article before possessives and anthroponomy is widely observed in Brazilian Portuguese (BP), this is what makes the Brazilian Portuguese different from the European Portuguese (EP) - because in the EP the article must be marked in this context. Several studies developed in Brazil, generally, relate this variation to the specificity. So are advancing in the analysis some studies that point to others conditioning aspects about the presence or absence of the article, such as the studies developed by Callou and Silva (1997). In this academic article, aiming to contribute for a facilitation of the understanding about this subject, we present the partial results of a survey that has been developed under
\end{abstract}

*Mestranda do Programa de Pós-graduação em Estudos Linguísticos da UEFS e licenciada em letras pela UEFS. E-mail: carvalho.rosana@hotmail.com.

** Professora Adjunto B do Departamento de Letras e Artes da Universidade Estadual de Feira de Santana/UEFS, Bahia/Brasil marianafag@gmail.com.

*** Professora Plena do Departamento de Letras e Artes da Universidade Estadual de Feira de Santana/UEFS, Bahia/Brasil zenaide.novais@gmail.com. 
the Master's Program in Linguistics from the State University of Feira de Santana (PPGEL / UEFS) aiming to analyze the presence or absence variation of the article, defined in 91 letters wrote by semi-literate persons and , edited by Santiago (2012), a corpus extremely relevant to the linguistic studies because is a graphic products of semi-literate persons and it also can be able to provide evidences of the Popular Brazilian Portuguese.

Keywords: Lexicon. Bahia. Angola. Influence. Language.

\section{PALAVRAS INICIAIS}

A reconstrução da sócio-história linguística do português brasileiro (PB), necessariamente, deve abranger os estudos do polo culto e do polo popular (MATTOS \& SILVA, 2002). Como destaca Santiago (2013), para o estudo da vertente culta do PB, as fontes disponíveis são extensas. Por outro lado, as pesquisas sobre as variantes populares esbarram na carência de materiais. O corpus constituído por Santiago (2012) contribui para amenizar tal lacuna. Neste trabalho, apresentam-se os resultados parciais de um estudo em desenvolvimento a partir desse corpus. Trata-se de uma pesquisa que está sendo executada no âmbito do Programa de Mestrado em Estudos Linguísticos da Universidade Estadual de Feira de Santana (PPGEL/UEFS), sobre a variação presença/ausência do artigo definido (AD) antes de possessivos e antropônimos.

$A$ variação no uso do $\mathrm{AD}$ é amplamente observada no $\mathrm{PB}$, distinguindo-o do português europeu (PE), que marca obrigatoriamente o artigo antes de possessivos e antropônimos. No PB, esse fenômeno ainda é pouco explorado. Os trabalhos pioneiros da professora Giselle Machline Oliveira e Silva (1982, 1998a, 1998b) contribuíram significativamente para compreensão do mesmo, mas ainda há um longo caminho a ser percorrido. A análise desse tema, a partir de textos de pessoas com pouca habilidade em escrita - mãos inábeis - pode contribuir para ampliação das observações alçadas até o momento.

A análise preliminar da variação dos AD nas cartas escritas por mãos inábeis do sertão baiano mostra que a presença do AD antes de possessivos é significativamente superior à sua ausência. Por outro, a presença de AD antes de antropônimo é marginal no corpus analisado, o que reflete aspectos do português arcaico, cuja presença de artigo antes de antropônimos, como mostra Costa (2002), era insignificante.

\section{FONTES PARA O ESTUDO DO PORTUGUÊS POPULAR BRASILEIRO}

A professora Rosa Virgínia Mattos e Silva, além das exímias contribuições para a reconstrução da sócio-história da Língua Portuguesa em geral, sobretudo do português quinhentista, bem como do $\mathrm{PB}$, através de vasto acervo de análises sobre diversos fenômenos, lançou ainda algumas pautas de pesquisa que têm orientado a condução de diversos estudos, inclusive no que concerne o rastreamento de fontes para investigações linguísticas.

Segundo Mattos e Silva (2002), para reconstrução da sócio-história linguística brasileira, as diferentes frentes de pesquisa devem abranger o estudo das variantes 
populares do PB “[...] não só as urbanas, como vem sendo feito pela Sociolingüística, mas nas suas variedades rurais de todo o Brasil, conectando o estudo dos usos do presente com a história das comunidades rurais" (MATTOS \& SILVA, 2002, p. 457). A autora esclarece ainda que é preciso "pesquisar no espaço brasileiro as variedades conviventes hoje sobretudo as dos não escolarizados das diversificadas áreas rurais do Brasil” (MATTOS \& SILVA, 2002, p. 461-462).

Destaca-se, contudo, que não é fácil encontrar materiais que contemplem as sugestões de Mattos e Silva, mesmo porque, durante a maior parte da história do Brasil, saber ler e escrever foi privilégio de uma minoria, favorecida social e economicamente. Com isso, os documentos escritos do passado raramente foram produzidos por classes subalternas, que poderiam expressar as variantes populares do português. Tal constatação destaca também a importância dos produtos gráficos de pessoas pouco familiarizadas com a escrita, que podem refletir aspectos de uma escrita cotidiana e, consequentemente, permitir uma aproximação com dados da oralidade. Quando consideradas amostras de língua oral, as dificuldades para constituição de corpora são ainda maiores. Sobre esses dados, Afrânio Barbosa (2006) destaca que

Se não pudemos supor um produto escrito completamente isento de tradições discursivas, podemos supor que o mais distante de tradições bem definidas, a escrita cotidiana, seja o mais próximo que a modalidade escrita pode estar da oralidade; podemos supor que, por ele, captaremos usos mais salientes da norma geral vernácula (BARBOSA, 2006, p. 763)

Os textos representativos dessa escrita menos monitorada têm especial interesse para a Linguística Histórica. Diante da impossibilidade de constituir corpora orais de sincronias passadas, esses materiais possuem relevância significativa porque podem refletir aspectos da língua oral. Isso remete a uma célebre colação da professora Rosa Virgínia Mattos e Silva, a de que "[...] sem a fala não se escreve, pode-se entrever ou entreouvir a vOz através dos textos: tarefa difícil e apenas aproximativa, 'ouvir o inaudível"' (MATTOS \& SILVA, 2008, p. 20).

Algumas iniciativas pioneiras têm conseguido ultrapassar as dificuldades em localizar produtos gráficos daqueles que estiveram à margem do processo de escolarização. Como exemplo, cita-se o trabalho realizado por Oliveira (2006), em sua tese de doutoramento, intitulada Negros e escrita no Brasil do século XIX: sócio-história, edição filológica de documentos e estudo linguístico. Nesse estudo, além da edição criteriosa de 290 documentos inéditos, escritos por africanos e afrodescendentes na Bahia, pertencentes à Sociedade Protetora dos Desvalidos, irmandade negra do século XIX, o autor realizou um estudo de aspectos de aquisição da escrita dos redatores.

Mas as contribuições de Oliveira não param por aí, visto que, além do material utilizado em sua tese, o autor reuniu outros documentos representativos do português popular, listados a seguir:

a) 14 textos (13 cartas e uma procuração) escritos por escravos oriundos de diferentes lugares da Bahia;

b) 183 tábuas votivas e 
c) 34 cartas e bilhetes escritos por cangaceiros, entre 1900 e 1940 (OLIVEIRA, 2009b).

Santiago (2012) também teceu importante contribuição para a constituição de corpus que pudesse servir ao estudo do português popular. Em sua dissertação de mestrado, intitulada Um estudo do português popular brasileiro em cartas pessoais de "mãos cândidas" do sertão baiano, a autora realizou a edição de 91 cartas pessoais, escritas por 43 lavradores de áreas rurais do semiárido baiano, e, à semelhança de Oliveira (2006), apresentou um estudo de aspectos da aquisição da escrita dos remetentes, do que foi possível caracterizá-los como mãos inábeis ${ }^{1}$. Sobre o corpus reunido por Santiago (2012), Santiago e Carneiro (2016, p. 91) explicam que "as cartas foram trocadas em relação de simetria entre redatores que fazem parte de um contexto sociocultural semelhante e são textos próximos de uma escrita cotidiana, de caráter afetivo, apresentando um significativo grau de transparência aos usos vernáculos”.

Barbosa (2006) explica que alguns documentos tornam-se significativos porque, além de ultrapassar dificuldades encontradas para a construção de corpora de sincronias passadas,

1) sabe-se serem verdadeiramente autógrafos; 2) sabe-se a naturalidade de todos seus autores; 3) sabe-se de que tradição discursiva (oficial, religiosa, etc.) são oriundos, e contase com a descrição de seus principais ritos e fórmulas; 3) foi-se capaz de contrapor homens a mulheres; 4) conta-se com grande volume de fólios distribuídos por longo período, o que permite estudo diacrônico com vários pontos de comparação (BARBOSA, 2006, 762).

Apontando esses e outros aspectos, o autor acrescenta que alguns materiais “[...] são mais que significativos, são representativos, pois além de um dos méritos citados, apresentam a qualidade de escrita de um grupo sócio-cultural de determinada época seja escrita cotidiana ou especial" (BARBOSA, 2006, 762). Essas observações foram destacadas aqui para ressaltar a relevância das cartas editadas por Santiago (2012), que, além de significativas, são representativas do português popular brasileiro, contemplando, além dos aspectos apontados por Mattos e Silva (2002), no início desta seção - são textos escritos por pessoas de baixa escolaridade, moradoras de áreas rurais - os tópicos indicados por Barbosa (2006).

As cartas dos inábeis do sertão baiano expressam "a qualidade de escrita” de um grupo que ficou à margem do processo de escolarização. A tabela a seguir apresenta os níveis de escolarização dos 43 remetentes das cartas:

Tabela 1 - A escolarização dos inábeis baianos

\begin{tabular}{lc}
\hline \multicolumn{1}{c}{ ESCOLARIZAÇÃO } & QUANTIDADE DE REDATORES \\
\hline Estudou pouco em casa & 26 \\
Estudou até a quarta série & 6 \\
\hline
\end{tabular}

1 Mãos inábeis é uma expressão de origem francesa, traduzida em português por Marquilhas (2000, p. 235), que utiliza o termo para se referir a adultos estacionados em fases iniciais de aquisição da escrita. 


\begin{tabular}{ll} 
Estudou apenas as primeiras séries & 2 \\
Aprendeu a ler e escrever com a leitura da & 1 \\
bíblia e pelo convívio com amigos & \\
escolarizados & 8 \\
Não há informações sobre a escolarização & \\
\hline
\end{tabular}

Fonte: Elaborada pela autora, a partir de Santiago (2011)

Lucchesi (2001) explica que, aproximadamente, na metade do século XX, a difusão do sistema de educação foi um dos aspectos que contribuiu para atenuar as diferenças entre os dois polos que constituem a realidade linguística brasileira, o polo culto e o polo popular. Como destaca Lucchesi (2015), essa "democratização" do ensino não atingiu todas as parcelas da população da mesma maneira. Ainda existem grupos subalternos que persistem às margens desse processo. Os inábeis baianos pertencem a um dos grupos aos quais a escolarização pouco afetou ${ }^{2}$.

Pelo pouco treino com a escrita, os remetentes das 91 cartas transpõem para a escrita muitas marcas da oralidade, como é possível observar no excerto a seguir, extraído de Santiago (2012):

(1) “[...] sim compadi $\mid$ u simhor sir puder| pargi A [.] |Farncico mota| Zacarias Er di ou | tar veizi [...] (AFS-3) $)^{3}$

A pouca habilidade dos remetentes com a escrita, revelada através de vários aspectos gráficos, supragráficos e de aquisição da escrita, apontados por Santiago (2012), torna seus produtos escritos de grande relevância para os estudos linguísticos. São esses materiais que permitem uma reconstrução aproximada do que teria sido o português falado pela parcela da população residente na zona rural do semiárido baiano, fornecendo indícios do que teria sido o português popular dessa região.

Tendo tecido essas observações, a seção seguinte apresenta os resultados parciais de uma pesquisa em desenvolvimento sobre o uso variável do $\mathrm{AD}$ nas cartas dos inábeis do sertão baiano, antes se aborda, brevemente, o fenômeno em estudo.

\section{A VARIAÇÃO DO AD NAS CARTAS DOS INÁBEIS DO SERTÃO BAIANO}

\subsection{SOBRE O FENÔMENO EM ESTUDO}

A variação no uso do $\mathrm{AD}$ antes de possessivos e antropônimos é um dos aspectos que diferencia o PB do PE. Enquanto que no PE a presença do artigo é obrigatória nesses dois contextos, sua presença é facultativa no $\mathrm{PB}$, como ilustram os exemplos a seguir:

${ }^{2}$ Sobre a criação de escolas no interior da Bahia ao longo do século XX, ver Carneiro e Almeida (2011).

${ }^{3}$ Os trechos extraídos do corpus editado por Santiago (2012) são referenciados pelo código de identificação do redator e pelo número da carta da qual foram extraídos. 
(2) [...] cando eu cega aqui Acarbo di armança| per min centa-porminnha Contas[...] (AFS-7)

(3) [...] compadi u s sinho tommi comta da minha| farmilha [...] (AFS-7)

(4) [...] nada mais du Ceu Derpezado| Conpadi Amigo ffarqinnho que er

u| Antonio Fortunato da Silva [...] (AFS-7)

(5) [...] lnblenbansa A João [.]| A Dão [...] (AFS-4)

No PB, as sentenças de dois a cinco são gramaticais e apresentam vasta variação entre as regiões. Já no PE apenas as sentenças (3) e (4), que apresentam o artigo definido antes de pronome possessivo e de antropônimo, são aceitas como corretas ${ }^{4}$.

No geral do $\mathrm{PB}$, a variação na ocorrência do $\mathrm{AD}$ se dá principalmente antes de possessivos e antropônimos, como destacado por Baxter e Lopes (2004). Em algumas comunidades com histórias sociolinguísticas particulares, como Helvécia - comunidade afro-brasileira, localizada no extremo sul da Bahia, que durante muito tempo preservou certo isolamento, de modo que as marcas do processo de transmissão linguística irregular ${ }^{5}$ mativeram-se bem perceptíveis nessa comunidade -, a variação de uso dos AD atinge os diversos sintagmas nominais.

Alguns dos primeiros estudos sobre esse fenômeno em variação no PB foram realizados pela professora Giselle Machline de Oliveira e Silva (1982, 1998a, 1998b). Seus trabalhos constituem um grande legado para a compreensão desse fenômeno. Segundo a autora, a variação no uso do AD antes de possessivos e antropônimos estaria condicionada por dois aspectos:

1 "A familiaridade que o falante supõe que o ouvinte tenha acerca da entidade mencionada" (SILVA, 1998a, p. 139) e

2 "A familiaridade que o falante tem acerca dessa entidade" (SILVA, 1998a, p. 139).

Esses aspectos são evidenciados pelo favorecimento à presença do $\mathrm{AD}$ diante de nomes de pessoas do conhecimento restrito do falante, de entidades inseridas pela primeiva vez no discurso (informações novas), e de sintagmas no singular e especificados, aspectos, enfim, relacionados ao grau de informação que o falante projeta

\footnotetext{
${ }^{4}$ Magalhães (2011) apresenta o percurso diacrônico do AD no PE, desde o século XVI até à generalização do uso no século XX. A autora destaca o início e o fim da variação presença/ausência do AD antes de possessivos em sintagmas com e sem preposição e antes de antropônimos.

${ }^{5}$ Lucchesi (2015) explica que o massivo contato linguístico que marcou o Brasil colônia não culminou na formação de uma variedade crioulizada do português. Segundo o autor, a formação polarizada do PB é consequência de um processo de transmissão linguística irregular, com intensa participação da camada africana da população, que transmitia para seus filhos uma variedade defectiva do português, adquirido como segunda língua em condições bem precárias. As consequências desse processo de transmissão linguística irregular são percebidas, sobretudo, na "erosão dos mecanismos gramaticais que não têm valor informacional, tais como as marcas de concordância nominal e verbal, a flexão de caso e as regras de movimento, mecanismos associados aos traços não interpretáveis na interface semântica" (LUCCHESI, 2015, p. 103).
} 
ser de seu ouvinte. De forma análoga, nomes próprios familiares, nomes de objetos que são inerentemente possuídos e de pessoas presentes no momento de enunciação $\left(1^{\mathrm{a}}\right.$ e $2^{\mathrm{a}}$ pessoas) fomentam mais a presenta do artigo. Nesse caso, o que está em questão é o nível de familiaridade que o próprio falante tem acerca da pessoa ou objeto referidos.

Em parceria com a professora Dinah Callou, em 1997, Giselle Silva realiza novo estudo. O objetivo das autoras era comparar a variação do AD antes de possessivos e antropônimos. Callou e Silva (1997) não encontraram semelhanças suficientes entre a variação nos dois contextos para afirmar se tratar de um mesmo fenômeno, mas identificaram alguns condicionamentos comuns à presença do $\mathrm{AD}^{6}$. A preposição foi um aspecto favorecedor nas duas análises, sobretudo preposições com as quais o $\mathrm{AD}$ pode se contrair. E a variável função sintática exibiu uma hierarquia semelhante para possessivos e antropônimos. As funções de tópico e sujeito foram favorecedoras nos dois casos. O estudo de Callou e Silva (1997) revelou ainda que a região de origem do falante exerce significativa influência sobre a variação. Como analisaram entrevistas do projeto NURC, as autoras puderam comparar os resultados encontrados para as cinco capitais contempladas pelo projeto. O gráfico exibe esses resultados:

Figura 1 - Efeito da Região de origem: peso relativo

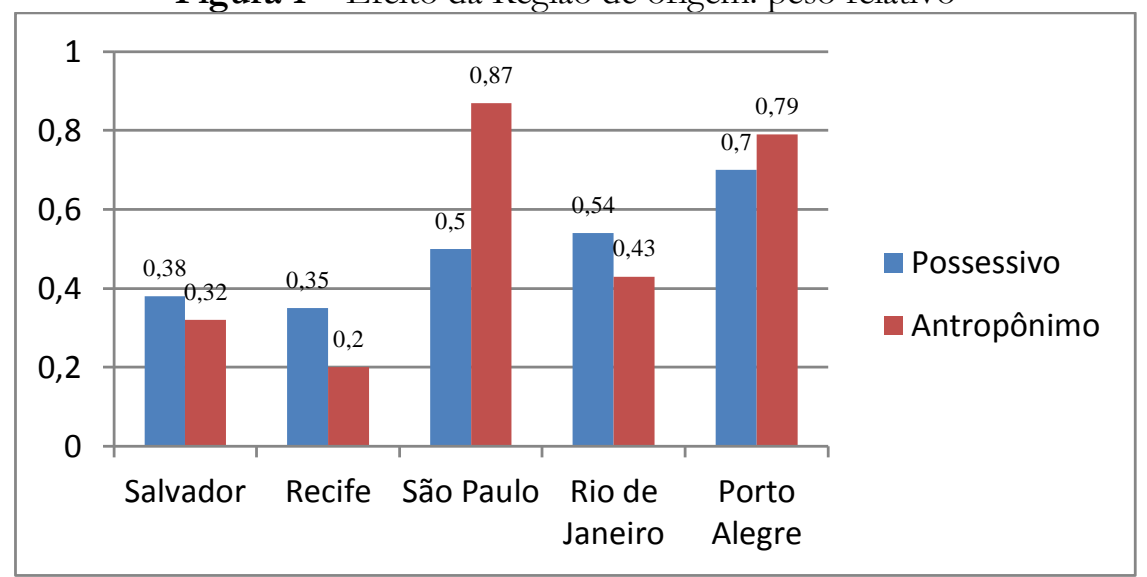

Fonte: Elaborado pela autora, a partir dos resultados apresentados em Callou e Silva (1997)

Os dados de Callou e Silva (1997) revelam algumas diferenças entre as cinco capitais. As capitais do Nordeste inibem a presença do AD antes de possessivos e antropônimos. As autoras levantam a hipótese de "essa distribuição regional poder apoiar-se na diferença de ritmo entre a fala do norte/nordeste e sul/sudeste do país, o que nos levaria à conclusão de a ocorrência do artigo, nesses contextos específicos, poder ter uma explicação que vai além da definitude" (CALLOU; SILVA, 1997, p. 25).

\footnotetext{
6 Sedrins (2013) também procurou comparar a variação de uso do AD antes de possessivos e antropônimos. Observando as diferenças entre a frequência de uso do $\mathrm{AD}$ antes de possessivos e de antropônimos em alguns estudos (Callou e Silva, 1997; Silva 1998b; Sedrins e Pereira, 2011), o autor explica que "os mecanismos da gramática que licenciam o artigo diante do contexto de possessivos prénominal diferem dos mecanismos que o licenciam diante de antropônimos" (SEDRINS, 2013, p. 135).
} 
Outro destaque do estudo de Callou e Silva (1997) está na constatação da influência de aspectos prosódicos na variação. Com isso, as autoras estendem a compreensão acerca do fenômeno, mostrando que, além da especificidade - apontada pelos diversos estudos sobre o AD desde Silva (1982) -, a variação do AD possui outros condicionantes.

$\mathrm{Na}$ subseção seguinte, apresentam-se os resultados parciais da variação no uso do $\mathrm{AD}$ nas cartas dos inábeis do sertão baiano.

\subsection{O AD EM TEXTOS DE MÃOS INÁBEIS: ANÁLISE PRELIMINAR}

Para análise da variação de uso do AD nas 91 cartas editadas por Santiago (2012), o primeiro passo foi selecionar os sintagmas em que é possível a variação. Com isso, eliminaram-se da análise os sintagmas em que o possessivo sucede o nome, como no exemplo abaixo:

(6) Aceite lembranças minhas.

Sobre essas ocorrências, Sedrins (2013) destaca que

No português, um possessivo posposto ao nome é incompatível com um sintagma de determinante encabeçado por um artigo definido, de forma que se um sintagma de determinante for encabeçado por um artigo definido no português e contiver um possessivo, este último será licenciado numa posição pré-nominal (SEDRINS, 2013, p. 137).

Também foram excluídas da análise as ocorrências de possessivos e antropônimos com função vocativa, visto que, como já fora observado por Silva (1982), em vocativo a ausência de AD é categórica antes de possessivo e antropônimo.

Com isso, somaram-se 403 ocorrências de pronomes possessivos em contexto de variação do $\mathrm{AD}$ nas cartas. A tabela abaixo apresenta a frequência de uso de cada pronome nas cartas:

Tabela 2 - frequência dos pronomes possessivos no corpus

\begin{tabular}{lccccc}
\hline Pronome & Meu & Teu & Seu & Nosso & Vosso \\
\hline Frequência & 187 & 17 & 161 & 32 & 6 \\
\hline
\end{tabular}

Fonte: Elaborada pela autora.

O uso do pronome seu em referência a $2^{\circ}$ pessoa do singular foi praticamente categórico. Apenas uma ocorrência foi em referência a $3^{\text {a }}$ pessoa, a qual não foi precedida pelo AD, ratificando a tendência apontada por Silva $(1982,1998 \mathrm{a})$ de que pronomes de terceira pessoa inibem a presença do AD. Essa ocorrência é apresentada a seguir:

(7) [...] tenho triteza por não viver | alegre como as outras vive com | seu espozo [...] (MDC- 84) 
Dos 403 sintagmas selecionados para análise, 246 apresentaram $\mathrm{AD}$, o que corresponde a $61 \%$ das ocorrências. A maior frequência de uso do $\mathrm{AD}$ foi a do pronome seu, como mostra o gráfico 2 :

Gráfico 2 - Frequência de AD diante de possessivo

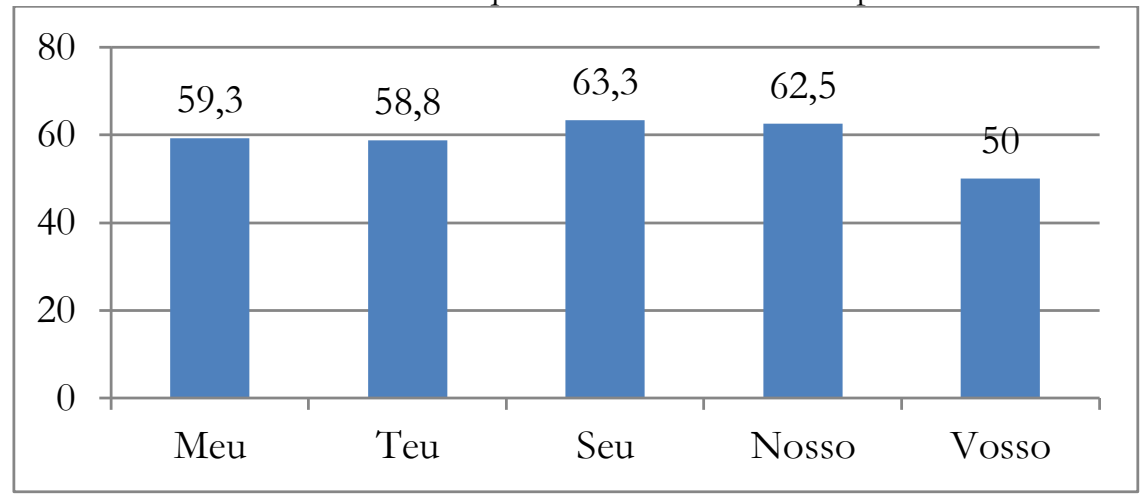

Fonte: Elaborado pela autora.

Em relação aos antropônimos, foram contabilizados 464 ocorrências de antropônimos em contexto de variação do AD. Dessas, apenas sete são precedidas pelo $\mathrm{AD}$, o equivalente a $1,5 \%$ do total. As ocorrências de antropônimos precedidos por $\mathrm{AD}$ são apresentadas a seguir:

(8) $[\ldots]$ nada mais du Ceu Derpezado | Conpadi Amigo ffarqinnho que er u Antonio Fortunato da Silva [...] (AFS- 7)

(9) [...] Compadi pitangeiro u $/$ senho jar largou conmigo | com Aderza ir com A | Dilinna [...] (AFS- 12)

(10) $\quad[. .$.$] Sim conpadi u sinho \mid$ min mandou Dizer $\mid$ que que Andriza conmeu A palha| da o Aririas [...] (AFS- 16)

(11) $[\ldots]$ nada mais du ceu $\mid$ C Ciraldos Conpadi que er $\mathbf{u} \mid \underline{\text { Antonio Fortunato }}$ da Silva $\mid[\ldots] \quad$ (AFS- 25)

(12) [...] madro dizre Agora Au Cero Josê ipere | ceu Amigro João dos Santos pelo u Cão Juau [...] (JS- 62)

(13) [...] i li Gea qui [.] Sifrodi manda a vosmece| i o Senhor farnani [...] (FP78)

(14) [...] Dei [.]Gea ao Senhor farnani[?] eu mando i mai [...] (FP- 78)

Das sete ocorrências de antropônimos precedidos por $\mathrm{AD}$, quatro foram do mesmo remetente, AFS, que passou alguns anos trabalhando em São Paulo. A explicação para a presença do AD nas cartas desse redator pode está nesse fato. No estudo de Callou e Silva (1997), São Paulo foi a capital que mais favoreceu a presença do $\mathrm{AD}$ antes de antropônimo. 
Em relação à variação do $\mathrm{AD}$ antes de antropônimos, os dados dos inábeis aproximam-se da variação observada por Costa (2002), em textos representativos do português arcaico. Costa (2002) analisou textos portugueses escritos entre os séculos XIII e XVI e identificou apenas duas ocorrências de antropônimos precedidos por artigo definido, de um total de 1466 ocorrências, o que corresponde a 0,13\% apenas.

\section{CONSIDERAÇÕES FINAIS}

O corpus constituído por Santiago (2012), representativo e significativo do português popular, contribui para amenizar a carência de corpora disponibilizados para estudo da vertente popular do PB. Os produtos gráficos de pessoas com baixa escolaridade têm especial valor para a Linguística Histórica por permitir uma aproximação com a oralidade e apresentar aspectos para caracterização do polo não culto do português brasileiro. Por isso, a pesquisa que foi apresenta aqui em suas fases iniciais destaca-se por colaborar, ainda que de forma singela, para a reconstrução da sócio-história linguística do PB.

A presença do AD antes de possessivo no corpus é significativa (61\%). A comparação - a ser realizada em análise futura - entre a frequência de uso do AD nas cartas dos inábeis com as frequências identificadas em outros estudos poderá fornecer uma visão mais ampla sobre a marcação do $\mathrm{AD}$ antes de possessivo no PB. A presença do $\mathrm{AD}$ antes de antropônimos apresentou frequência muito baixa no corpus. As mãos inábeis do sertão baiano não marcam o AD antes de nome próprio de pessoa.

\section{REFERÊNCIAS}

BARBOSA, A. G. Tratamento dos corpora de sincronias passadas da língua portuguesa no Brasil: recortes grafológicos e linguísticos. In: LOBO, T. et al. (Org.). Para a história do português brasileiro. v. 6, t. 2. Salvador: EDUFBA, 2006. p.761-780. Disponível em: <http://www.letras.ufrj.br/posverna/docentes/71719-1.pdf>. Acesso em: 3 jul. 2017. BAXTER, A.; LOPES, N. Variação no uso de artigos: uma comparação. In: XX JORNADA NACIONAL DE ESTUDOS LINGUÍSTICOS. 2004. João Pessoa. Anais da 20ªrnada Nacional de Estudos Linguísticos. João Pessoa: GELNE, 2004b. p. 43-52 Disponível em: <http://gelne.com.br/arquivos/anais/gelne2004/PDF/alan\%20N.\%20Baxter\%20e\%20norma\%20lopes.pdf>. Acesso em: 3 jul. 2017.

CALLOU, D.; SILVA, G. M. de O. e. O uso do artigo definido em contextos específicos. In: HORA, D. da (Org.). Diversidade Lingüistica no Brasil. João Pessoa: Idéia, 1997. p. 11-27.

CARNEIRO, Z. de O.; ALMEIDA, N. L. F. A criação de escolas a partir de critérios demográficos na Bahia do século XIX: uma viagem ao interior. In: NEVES, E. F. (Org.). Sertões da Bahia: formação social, desenvolvimento econômico, evolução política e diversidade cultural. Salvador: Editora Arcádia, 2011. 
COSTA, I. O uso do artigo definido diante de nome próprio de pessoa e de possessivo do século XIII ao século XVI. In: MATTOS \& SILVA, R. V.; MACHADO FILHO, A. V. L. (Org.). O português quinhentista: estudos linguísticos. Salvador: EDUFBA; Feira de Santana: UEFS, 2002, p. 284-306.

LUCCHESI, D. As duas grandes vertentes da história sociolingüística do Brasil (15002000). D.E.L.T. $A$ [online], v. 17, n. 1, p. 97-130, 2001. Disponível em:

<http://www.scielo.br/pdf/delta/v17n1/ a05v17n1.pdf>. Acesso em: 10 jun. 2015.

LUCCHESI, D. Norma linguística e realidade social. In: BAGNO, M. (Org.). Linguística da norma. São Paulo: Edições Loyola, 2002.

LUCCHESI, D. Lingua e sociedade partidas: a polarização sociolinguística no Brasil. São Paulo: Contexto, 2015.

MAGALHÃES, T. V. O uso de artigo definido diante de pronome possessivo em textos portugueses do século XVI a XIX. Leitura, n.47. Maceió, 2011, p. 123-143.

MATTOS \& SILVA, R. V. Para a história do português culto e popular brasileiro: sugestões para uma pauta de pesquisa. In: ALKMIM, T. M. (Org.). Para a história do português brasileiro. São Paulo: Humanitas/FFLCH, 2002, p. 443-464.

MATTOS \& SILVA, R. V. Ensaios para uma sócio-história do português brasileiro. São Paulo: parábola Editorial, 2004.

MATTOS \& SILVA, R. V. Caminhos da Linguística Histórica: ouvir o inaudível. São Paulo: Parábola Editorial, 2008.

SANTIAGO, H. da S. Cartas em Sisal. In: CARNEIRO, Z. de O. N.; SANTIAGO, H. da S.; OLIVEIRA, K. Cartas Brasileiras (1809-2000): coletâneas de fontes para o estudo do português: 3 (1906-2000). Feira de Santana: UEFS Editora, 2011. p. 19-59.

SANTIAGO, H da S. Um estudo do português popular brasileiro em cartas pessoais de "mãos cândidas" do sertão baiano. 2012. 2v. 256f. Dissertação (Mestrado em Estudos Linguísticos) - Programa de Pós-graduação em Estudos Linguísticos, Universidade Estadual de Feira de Santana, Feira de Santana. Disponível em: < https://issuu.com/prohpor/docs/disserta___o_huda_santiago_2012>. Acesso em: 3 jun. 2017.

SANTIAGO, H. da S. O estudo do português popular brasileiro: sobre algumas fontes. Revista Pandora Brasil. No 52 Março de 2013. "Português brasileiro: algumas histórias" ISSN 2175-3318. Disponível em: <http://revistapandorabrasil.com/revista_pandora/portugues_brasileiro/huda.pdf $>$. Acesso em: 09 jun. 2017.

SANTIAGO, H. da S.; CARNEIRO, Z. de O. N. Fontes para uma sócio-história linguística do português popular: as cartas de mãos inábeis do sertão baiano. A Cor das Letras, v. 17, n.1. Feira de Santana, p. 90-98, dez. 2016. Disponível em: < http://periodicos.uefs.br/index.php/acordasletras/article/view/1440>. Acesso em: 3 jun. 2017.

SEDRINS, A. P. O artigo definido no português brasileiro em contexto de antropônimos e possessivos pré-nominais. In: MOURA, D.; SIBALDO, M. A. (Org.). Para a história do português brasileiro. Maceió: EDUFAL, 2013. p. 133-149. 
SILVA, G. M. de O. e. Estudo da regularidade na variação dos possessivos no português do Rio de Janeiro. 1982. Tese (Doutorado em Letras) - Universidade Federal do Rio de Janeiro, Rio de Janeiro, 1982.

SILVA, G. M. de O. e. Realização facultativa do artigo definido diante de possessivo e de patronímico. In: SILVA, G. M. de O. e; SCHERRE, M. M. P. (Org.). Padrões sociolingüisticos: análise de fenômenos variáveis do português falado na cidade do Rio de Janeiro. Rio de Janeiro: Tempo Brasileiro, 1998a. p. 120-145.

SILVA, G. M. de O. e. Emprego do artigo diante de possessivo e de patronímico: resultados sociais. In: SILVA, G. M. de O. e; SCHERRE, M. M. P. (Org.). Padrões sociolingüisticos: análise de fenômenos variáveis do português falado na cidade do Rio de Janeiro. Rio de Janeiro: Tempo Brasileiro, 1998b. p. 265-281.

Recebido em: 05/06/2018

Aprovado em: 23/07/2018

Publicado em: 31/12/2018 